\title{
CONTRIBUTION OF TRAFFIC AND TOBACCO SMOKE IN THE DISTRIBUTION OF POLYCYCLIC AROMATIC HYDROCARBONS ON OUTDOOR AND INDOOR $\mathrm{PM}_{2.5}$
}

\author{
D. CASTRO ${ }^{1,2}$ \\ K. SLEZAKOVA ${ }^{1}$ \\ C. DELERUE-MATOS ${ }^{2}$ \\ M.C. ALVIM-FERRAZ ${ }^{1}$ \\ S. MORAIS ${ }^{2}$ \\ M.C. PEREIRA ${ }^{1, *}$
}

Received: 09/12/09

Accepted: 16/02/10

\author{
${ }^{1}$ LEPAE/Faculdade de Engenharia da Universidade do Porto, \\ Rua Dr. Roberto Frias, 4200-465 Porto, Portugal \\ ${ }^{2}$ REQUIMTE, Instituto Superior de Engenharia do Porto, \\ Rua Bernardino de Almeida, 431, 4200-072 Porto, Portugal
}

\section{ABSTRACT}

Traffic emissions and tobacco smoke are considered two main sources of polycyclic aromatic hydrocarbons (PAHs) in indoor and outdoor air. In this study, the impact of these sources on the level of fine particulate matter $\left(\mathrm{PM}_{2.5}\right)$ and on the distribution of $15 \mathrm{PAHs}$ regarded as priority pollutants by the US-EPA on $\mathrm{PM}_{2.5}$ were evaluated and compared.

Outdoor and indoor $\mathrm{PM}_{2.5}$ samples were collected during winter 2008 in Oporto city in Portugal, for sampling periods of 12 and 24 hours, respectively. The outdoor $\mathrm{PM}_{2.5}$ were sampled at one site directly influenced by traffic emissions and the indoor $\mathrm{PM}_{2.5}$ samples were collected at one home directly influenced by tobacco smoke and another one without smoke. A methodology based on microwave-assisted extraction and liquid chromatography with fluorescence detection was applied for the efficient PAHs determination in indoor and outdoor $\mathrm{PM}_{2.5}$.

$\mathrm{PAHs}$ in indoor $\mathrm{PM}_{2.5}$ concentrations were significantly influenced by the presence of traffic and tobacco smoking emissions. The mean of $\Sigma \mathrm{PAHs}$ in the outdoor traffic $\mathrm{PM}_{2.5}$ was not significantly different from the value attained in the indoor without smoking site.

The tobacco smoke increased significantly PAHs concentrations on average about 1000 times more, when compared with the outdoor profile samples suggesting that tobacco smoking may be the most important source of indoor PAHs pollution.

KEYWORDS: Indoor and outdoor air, PAHs, $\mathrm{PM}_{2.5}$, tobacco smoke, traffic emissions.

\section{INTRODUTION}

The quality of indoor and outdoor air is an increasingly strong concern related to the public health since the cases of problems directly caused by human exposure to polluted air continue to increase in Europe (Directive 2004/107/EC, 2005).

Airborne suspended particulate matter (PM) is an important marker of air quality. It is a mixture of various sized ambient particles that have potentially toxic compounds associated with them. Several research studies seem to indicate that PM is associated with negative respiratory responses. The size of particles is a particular important factor since it determines the place where particle deposition occurs in the respiratory system. The smaller particles, such as $\mathrm{PM}_{2.5}$ (particles with an aerodynamic diameter smaller than 2.5 micrometers), can penetrate in the deeper parts of the lungs, causing pulmonary diseases, lung cancer and premature mortality and morbidity (Ravindra et al., 2001). The composition of $\mathrm{PM}_{2.5}$ includes organic and inorganic matter, nitrogen and sulphur compounds, several heavy metals, 
radionuclides and polycyclic aromatic hydrocarbons (PAHs) (Slezakova et al., 2007; Slezakova et al., 2009a; Slezakova et al., 2009b).

PAHs are regarded as priority pollutants by the U.S. Environmental Protection Agency, since some of them are classified as carcinogenic and mutagenic (EPA, 1986; IARC, 2002; IARC, 2008). These compounds are composed by two or more fused aromatic rings and mostly formed during incomplete combustion of organic materials (Maliszewska-Kordybach, 1999; Mastral and Callen, 2000). The largest PAHs sources to the atmosphere include emissions from automobiles (traffic emissions; Cacciola et al., 2002; Hien et al., 2007; Kishida et al., 2008), industrial processes and wood burning.

Indoor air pollution has taken public attention during the last two decades because people spend more than $80 \%$ of their time in indoor environments (homes, schools, offices and restaurants). Indoor air is also polluted by PAHs, which come not only from outdoor air through natural and mechanical (without filters) ventilation, but also indoor emission sources such as cooking, heating and tobacco smoking. The combustion of tobacco generates inhalable particles that are strongly associated with toxic compounds such as PAHs (Lung et al., 2004), especially those with highest molecular weights, which are the most carcinogenic (EPA, 1986; IARC, 2002; IARC, 2008). This source is considered by some authors the most important indoor PAHs source (WHO, 2000; Ohura et al., 2004; Lung et al., 2004). However, passive smoking has also become an important health issue; in Western countries, with an adult smoking prevalence of $30-50 \%$, it is estimated that over $50 \%$ of homes are occupied by at least one smoker (WHO, 2000), resulting in a high prevalence of environmental tobacco smoke exposure, that increases the risk of developing asthma by $40-200 \%$ (Bernstein et al., 2008).

Concerning the influence of outdoor air on indoor air quality, studies revealed that the presence of potentially carcinogenic PAHs (4-6 rings) in indoor air can be strongly associated with infiltration of PAHs from outdoor air originated mainly by vehicle emissions (Fischer et al., 2000; Sanderson and Farant, 2004). Diffusion of pollutants from outdoor air to indoor air is influenced by several factors such as geographic location, concentration of pollutants in outdoor air, type of residence and type of ventilation.

As the quality of indoor air has an important impact on human health, there is a special interest in analysing the exposure to PAHs in indoor environments and evaluating the influence of the main indoor emission sources. Several studies indicated that PAH concentrations in indoor air can be higher that in outdoor air with certain combustion sources (Liu et al. 2001), but few studies examined the indoor/outdoor relationships of PAH concentrations with respect to main outdoor sources, as traffic emissions.

The aim of this work was to evaluate and compare the contribution of the main PAHs and $\mathrm{PM}_{2.5}$ sources, namely, traffic and tobacco smoking, on the distribution of $15 \mathrm{PAHs}$ in outdoor and indoor $\mathrm{PM}_{2.5}$.

\section{EXPERIMENTAL DESCRIPTION}

\subsection{Sampling}

The monitoring of outdoor and indoor $\mathrm{PM}_{2.5}$ was conducted during winter 2008 for 14 and 21 consecutive days, respectively, in Paranhos district of Oporto city in Portugal.

The outdoor $\mathrm{PM}_{2.5}$ were sampled at one site directly influenced by traffic emissions due to the proximity of one highway and others important roads (Figure 1). This place was chosen since the traffic density during morning peak hours is high given its proximity to a central hospital and several high schools and Universities. Consequently, traffic emissions are the main source of atmospheric pollutants (Pereira et al., 2005). The monitoring equipment was located at the entrance of a car parking area of one of the universities, at about $50 \mathrm{~m}$ east of one of the main streets.

The indoor $\mathrm{PM}_{2.5}$ samples were collected at one home directly influenced by tobacco smoke and another one considered as reference (non smoking site). Both homes were $1 \mathrm{~km}$ far from the outdoor traffic site. Mechanical ventilation did not exist at both monitoring sites so natural ventilation was provided by opening windows as occupants thought necessary. To avoid dissimilar influence of outdoor PM, both monitoring places were selected in the same block of 
apartments, and on the same floor $\left(4^{\text {th }}\right)$. The same domestic activities were kept in the two indoor environments, namely number of occupants (2), cleaning (three times per week), frequency of cooking (once per day in electric cooker) and absence of heating.

The particles were collected on polytetrafluoroethylene membrane filters with $2 \mu \mathrm{m}$ of porosity for sampling periods of 12 hours (indoor) and 24 hours (outdoor), using TCR TECORA Bravo $\mathrm{H} 2$ constant flow samplers, combined with PM EN LVS sampling heads, in compliance with the norm EN 14907 (for $\mathrm{PM}_{2.5}$ ) (Slezakova et al., 2007). A sampling air flow rate of $2.3 \mathrm{~m}^{3} \mathrm{~h}^{-1}$ was applied. After sampling, the samples were stored at $-20^{\circ} \mathrm{C}$ and were protected from light until analysis.

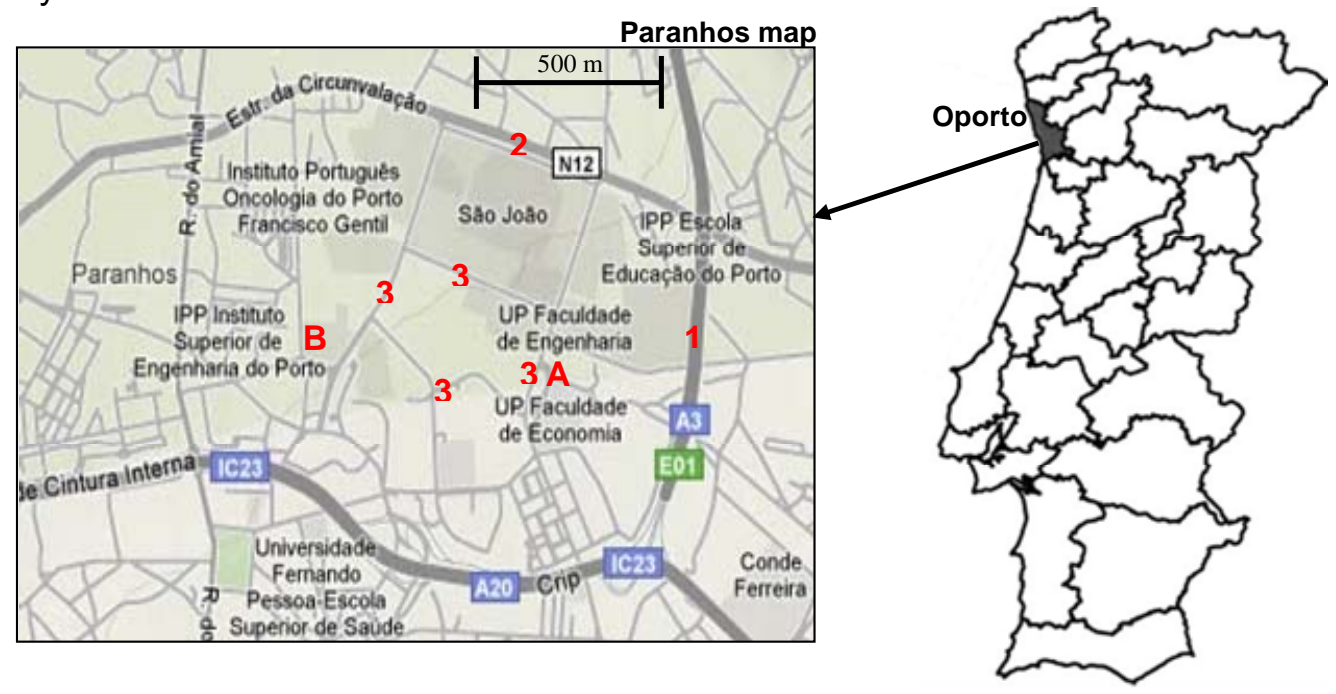

Figure 1. Map of Portugal and Paranhos with the locations of the monitoring sites: A- outdoor site; B- indoor site (with and without smoking); 1- highway; 2- thoroughfares; 3- main streets

\subsection{PAHs analysis}

Extractions of PAHs from the indoor and outdoor $\mathrm{PM}_{2.5}$ samples were performed by microwave-assisted extraction (MAE; MARS-X 1500 W Microwave Accelerated Reaction System for Extraction and Digestion, CEM, Mathews, NC, USA) applying the previously optimised conditions (Castro et al., 2009). Briefly, $30.0 \mathrm{~mL}$ of acetonitrile (Lichrosol for gradient elution, Carlo Erba, Rodano, Italy, purity > 99.9\%) were used at $110^{\circ} \mathrm{C}$ during an extraction time of $20 \mathrm{~min}$. This approach supports sustainable development as it permits the use of lower toxicity solvents, require less energy and solvent than conventional processes, while generating fewer wastes. Extracts, after evaporation to dryness and redissolution in $1000 \mu \mathrm{L}$ of acetonitrile, were analysed by liquid chromatography with fluorescence detection (Shimadzu LC system and fluorescence detector RF-10AXL, Shimadzu Corporation, Kyoto, Japan). Separation of the compounds was performed in a C18 column (YMC, MP-PAH C18, $50 \times 4.0 \mathrm{~mm} ; 3 \mu \mathrm{m}$ particle size). Fluorescence wavelength programming was used to perform better sensitivity and minimal interference. The excitation/emission wavelength pair of $260 / 315 \mathrm{~nm}$ was selected for initial time, at $8.0 \mathrm{~min}$ it was changed to $260 / 366 \mathrm{~nm}$, at $9.0 \mathrm{~min}$ to $260 / 430 \mathrm{~nm}$ and at $18.8 \mathrm{~min}$ to $290 / 505 \mathrm{~nm}$. The injected volume was $15.0 \mu \mathrm{L}$ (Castro et al., 2009). External calibrations with PAHs mixed standards, using at least 6 calibration points, were performed. Analytical blanks were handled using the same procedures as those applied for the collected samples. Blank levels of individual PAHs were in most cases undetectable. Each analysis was run at least in triplicate. Limits of detection between 0.0016 $\mathrm{ng} \mathrm{m}^{-3}\left(0.090 \mu \mathrm{g} \mathrm{L}^{-1}\right)$ for benz[a]anthracene and $0.027 \mathrm{ng} \mathrm{m}^{-3}\left(1.5 \mu \mathrm{g} \mathrm{L}^{-1}\right)$ for naphthalene were obtained, with corresponding limits of quantification in the range $0.0054-0.089 \mathrm{ng} \mathrm{m}^{-3}$ (0.30-4.90 $\mu \mathrm{g} \mathrm{L}^{-1}$ ). The previously optimized analytical methodology (Castro et al., 2009) provided evidence that acceptable recoveries (between $82.8 \pm 4.5$ to $101.0 \pm 4.7 \%$ for all compounds except for naphthalene, $56.7 \pm 9.1 \%$, and anthracene, $66.7 \pm 7.2 \%$ ) and repeatability (between $0.2 \%$ for acenaphthene and $4.2 \%$ for pyrene) are achieved for all PAHs. The reproducibility (between-day precision) of the analysis was also evaluated by 
repeating the analysis of spiked samples on three consecutive days. Values of RSD ranging from $1.1 \%$ for indeno[1,2,3-cd]pyrene and $7.6 \%$ for chrysene were reached.

For the data treatment, the Student's t-test was applied to determine the statistical significance $(P<0.05$, two tailed) of the differences between the determined means.

\section{RESULTS AND DISCUSSION}

\section{1 $\mathrm{PM}_{2.5}$ concentration}

The statistical analysis of $\mathrm{PM}_{2.5}$ concentrations measured during the experimental measurements at the outdoor site influenced by traffic emissions, and at the indoor sites without and with the influence of tobacco smoking emissions are presented in Figure 2.

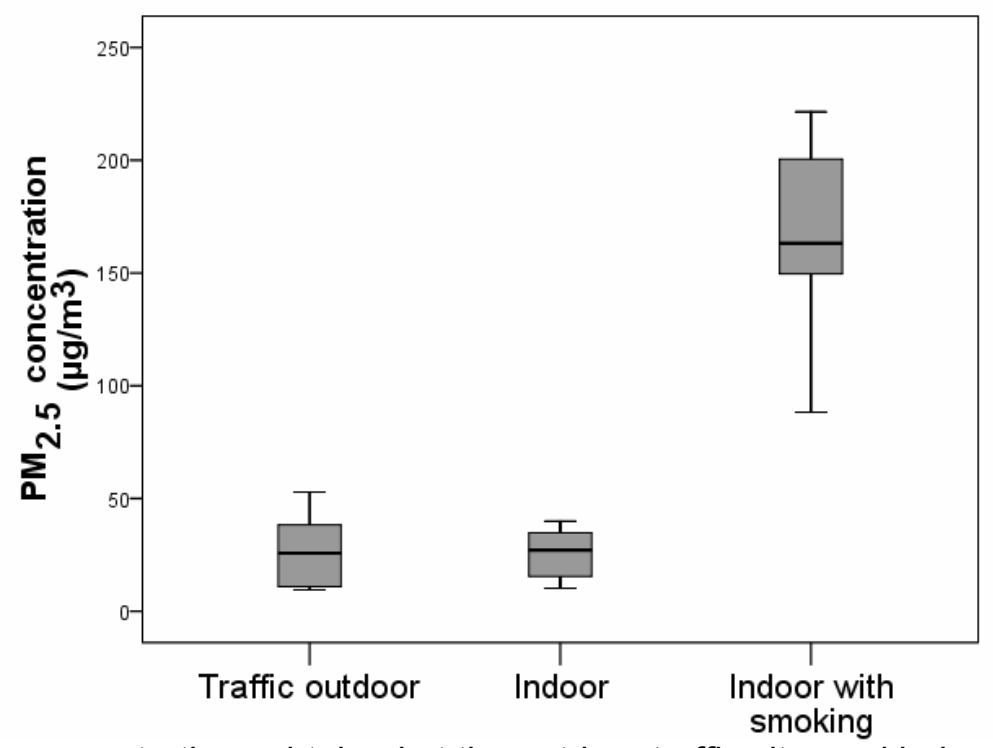

Figure 2. $\mathrm{PM}_{2.5}$ concentrations obtained at the outdoor traffic site, and indoor non smoking and smoking sites. Boxes show 25th to 75th percentiles, lower and upper bars show minimum and maximum values, and lines inside the boxes show the mean concentration

$\mathrm{PM}_{2.5}$ concentration means at the outdoor traffic site and at the indoor non smoking site ranged between 9.5 to $52 \mu \mathrm{g} \mathrm{m}^{-3}$ and 10 to $40 \mu \mathrm{g} \mathrm{m}^{-3}$, with mean concentrations and standard deviations of $26 \pm 14$ and $26 \pm 10 \mu \mathrm{g} \mathrm{m}^{-3}$, respectively. These concentration differences were not statistically significant showing that the $\mathrm{PM}_{2.5}$ concentrations in both sites were very similar. This fact reflects that the levels of indoor $\mathrm{PM}_{2.5}$ are influenced by traffic-related emissions. These results are in agreement with those reported by Diapouli et al. (2008), that conducted simultaneous indoor and outdoor measurements of $\mathrm{PM}_{10}$ and $\mathrm{PM}_{2.5}$ in the center of Athens. They concluded that indoor concentration levels are mainly affected by PM of outdoor origin, since the calculated indoor-to-outdoor concentrations ratios were much lower than 1.00 during all days of their experiment. Furthermore, in their study, indoor and outdoor concentrations were highly correlated.

$\mathrm{PM}_{2.5}$ concentration mean at the indoor smoking site ranged between 88 to $440 \mu \mathrm{g} \mathrm{m}^{-3}$, with a mean and a standard deviation of $197 \pm 103 \mathrm{\mu g} \mathrm{m}^{-3}$. In this indoor ambience, the tobacco smoking emissions were responsible for the significant increase of $\mathrm{PM}_{2.5}$ concentrations near $700 \%$, compared with both the indoor non smoking and the outdoor traffic sites.

The indoor-to-outdoor $(I / O)$ ratio gives an idea of the relative contribution of indoor and outdoor sources to the indoor concentration levels. I/O ratio $>1$ indicates that the indoor sources make a significant contribution to indoor air concentrations, while in the absence of strong indoor sources this ratio is expected to be close or lower than 1 (Ilgen et al., 2001).

The obtained $/ / O \mathrm{PM}_{2.5}$ concentration ratio considering indoor non smoking was 0.98 . This value indicated the absence of significant indoor sources related with domestic activities as cooking, cleaning and heating. Thus, for $\mathrm{PM}_{2.5}$ the outdoor air affects significantly the 
composition of indoor air, leading almost to equilibrium between indoor and outdoor air. $\mathrm{PM}_{2.5}$ can be infiltrated and transported easily from outdoor to indoor through the natural ventilation, because of their small size. This PM fraction is of great health concern, since when inhaled, it can be deposited deeply in the lungs (Ravindra et al., 2001). Thus, it is important to develop strategies to improve the outdoor air quality and consequently this would be also reflected in the enhancement of the indoor air quality.

In the ambience affected by tobacco smoke the $I / O \mathrm{PM}_{2.5}$ concentration ratio was 7.7 . This value is indicative that tobacco smoking is the dominant source for the significant increase of indoor $\mathrm{PM}_{2.5}$ concentrations.

\subsection{PAHs distribution}

The statistical analysis of individual PAH and the total PAHs ( $\mathrm{PAHs}$ ) concentrations, in $\mathrm{PM}_{2.5}$, measured during the experimental measurements at the outdoor traffic site, and at indoor non smoking and indoor smoking sites are presented in Table 1.

The mean of $\Sigma P A H s$ found in the outdoor traffic $\mathrm{PM}_{2.5}$ samples during the experimental measurement was $121 \times 10^{2} \mathrm{pg} \mathrm{m}^{-3}$. In the indoor samples without smoking the $\Sigma \mathrm{PAHs}$ mean was not significantly different to the outdoor traffic $\left(107 \times 10^{2} \mathrm{pg} \mathrm{m}^{-3}\right)$. These data evidenced that the presence of PAHs in indoor environments was influenced by outdoor air pollution that spreads to the interior of the spaces through natural ventilation.

The influence of tobacco smoke increased significantly the $\Sigma P A H s$ to $918 \times 10^{2} \mathrm{pg} \mathrm{m}^{-3}$, pointing to be the major PAHs indoor source. This evidence allowed concluding that tobacco smoke strongly increased $\Sigma \mathrm{PAHs}$ in $\mathrm{PM}_{2.5}$.

Fuorene, anthracene, benzo[b]fluoranthene, benzo[k]fluoranthene, benzo[a]pyrene, dibenz[a,h]anthracene, benzo[g,h,i]perylene and indeno[1,2,3-cd]pyrene concentration levels were not significantly different at outdoor traffic and indoor non smoking sites. It is interesting to notice that the PAHs with more aromatic chains (5-6 rings) were majority found in $\mathrm{PM}_{2.5}$ samples collected in outdoor traffic and indoor non smoking sites. The sum of these PAHs corresponds to ca. $70 \%$ and $87 \%$ of the $\Sigma \mathrm{PAHs}$, for the outdoor traffic and indoor non smoking sites, respectively.

A detailed analysis of each PAH permitted concluding that dibenz[a,h]anthracene, a possible indicator of traffic emissions (Rehwagen et al., 2005) was the PAH more abundant during outdoor traffic and indoor non smoking experimental measurements and corresponds to ca. $29 \%$ and $43 \%$ of $\Sigma P A H s$, respectively. It seems that dibenz[a,h]anthracene was not affected by the presence of tobacco smoke since in the indoor smoking experimental measurement it was determined in levels below those detected under the influence of traffic.

According to some authors chrysene, benzo[b]fluoranthene, benzo[a]pyrene, dibenz[a,h]anthracene, benzo[g,h,i]perylene and indeno[1,2,3-cd]pyrene (PAHs with high molecular weight), are indicators of traffic emissions and are strongly associated to emissions from incomplete motor combustion (Dallarosa et al., 2008; Guo et al., 2003). The benzo[a]pyrene/ benzo[g,h,i]perylene mean ratios obtained were 0.81 and 0.66 , for outdoor traffic and indoor non smoking sites, respectively, which indicate the presence of diesel engines (Vardar et al., 2008). Furthermore, the mean values attained for the indeno[1,2,3cd]pyrene/(Indeno[1,2,3-cd]pyrene + benzo[g,h,i]perylene) ratio at both sites were approximately the same ( 0.55 for outdoor traffic site and 0.56 for indoor non smoking place) and greater than 0.3 confirming the occurrence of traffic emissions, especially from diesel engines (Guo et al., 2003). As most of PAHs composition on $\mathrm{PM}_{2.5}$ was similar on both places (outdoor traffic and indoor non smoking), it revealed the important influence of the outdoor pollution in indoor air quality. This is an interesting information because PAHs with higher molecular weight are considered more carcinogenic and dangerous for human health (EPA, 1986; IARC, 2002; IARC, 2008). 
Table 1. PAH concentrations measured in $\mathrm{PM}_{2.5}$ samples, collected in outdoor traffic, indoor non smoking and indoor smoking sites

\begin{tabular}{|c|c|c|c|c|c|c|c|}
\hline & & & & & & & \\
\hline \multirow[b]{3}{*}{ Compound } & \multirow[b]{3}{*}{$\begin{array}{l}\text { Number } \\
\text { of rings }\end{array}$} & \multicolumn{6}{|c|}{$\begin{array}{l}\text { Concentration } \\
\left(\times 10^{2} \mathrm{pg} \mathrm{m}^{-3}\right)\end{array}$} \\
\hline & & \multicolumn{2}{|c|}{$\begin{array}{l}\text { Outdoor traffic } \\
\qquad(n=3)\end{array}$} & \multicolumn{2}{|c|}{$\begin{array}{l}\text { Indoor non smoking } \\
\qquad(\mathrm{n}=3)\end{array}$} & \multicolumn{2}{|c|}{$\begin{array}{c}\text { Indoor smoking } \\
(\mathrm{n}=3)\end{array}$} \\
\hline & & Mean \pm SD & Min - Max & Mean \pm SD & Min - Max & Mean \pm SD & Min - Max \\
\hline Naphthalene & 2 & n.d. & n.d. & $1.12 \pm 0.78$ & n.d. -2.00 & $8.0 \pm 13.3$ & n.d. -34.1 \\
\hline Acenaphthene & 3 & n.d. & n.d. & n.d. & n.d. & $67.1 \pm 68.1$ & $19.2-285$ \\
\hline Fluorene & 3 & $0.260 \pm 0.190$ & $0.050-0.710$ & $0.180 \pm 0.070$ & $0.070-0.310$ & $0.920 \pm 0.690$ & $0.070-2.79$ \\
\hline Phenanthrene & 3 & $4.47 \pm 3.03$ & $0.920-10.8$ & $0.870 \pm 0.760$ & $0.030-2.46$ & $24.0 \pm 22.1$ & $7.08-90.8$ \\
\hline Anthracene & 3 & $7.85 \pm 5.91$ & $1.14-24.4$ & $3.54 \pm 2.33$ & $1.04-6.95$ & $36.7 \pm 43.8$ & $5.38-175$ \\
\hline Fluoranthene & 4 & $2.76 \pm 2.34$ & $0.620-7.69$ & $0.610 \pm 0.340$ & $0.120-10.4$ & $102.2 \pm 96.2$ & $32.1-376$ \\
\hline Pyrene & 4 & $5.14 \pm 3.78$ & $0.930-12.6$ & $1.64 \pm 1.06$ & $0.300-3.42$ & $136.5 \pm 143.1$ & $27.1-569$ \\
\hline Benz[a]anthracene & 4 & $6.54 \pm 4.94$ & $0.990-17.2$ & $1.74 \pm 0.97$ & $0.350-2.88$ & $56.9 \pm 41.7$ & $11.5-164$ \\
\hline Chrysene & 4 & $9.29 \pm 6.85$ & $1.30-23.8$ & $3.28 \pm 1.79$ & $0.650-5.69$ & $226.5 \pm 214.4$ & $30.2-704$ \\
\hline Benzo[b]fluoranthene & 5 & $13.4 \pm 9.7$ & $2.15-29.7$ & $8.83 \pm 4.80$ & $1.23-14.9$ & $50.9 \pm 24.0$ & $12.8-101$ \\
\hline Benzo[k]fluoranthene & 5 & $5.02 \pm 3.69$ & $0.740-10.6$ & $3.06 \pm 1.67$ & $0.380-5.03$ & $13.4 \pm 7.4$ & $4.93-30.2$ \\
\hline Benzo[a]pyrene & 5 & $8.47 \pm 6.55$ & $0.950-21.8$ & $7.83 \pm 4.09$ & $1.07-12.2$ & $86.0 \pm 55.7$ & $15.5-230$ \\
\hline Dibenz[a,h]anthracene & 5 & $34.7 \pm 24.0$ & $2.70-68.1$ & $46.5 \pm 25.9$ & $4.78-81.2$ & $14.9 \pm 14.3$ & $3.48-41.8$ \\
\hline Benzo[g,h,i]perylene & 6 & $10.5 \pm 7.7$ & $0.740-23.1$ & $11.9 \pm 6.7$ & $1.43-21.7$ & $45.2 \pm 28.7$ & $7.30-111$ \\
\hline Indeno[1,2,3-cd]pyrene & 6 & $13.0 \pm 9.6$ & $0.590-26.5$ & $15.4 \pm 8.7$ & $1.61-27.6$ & $48.4 \pm 24.9$ & $13.2-109$ \\
\hline$\sum \mathrm{PAHs}$ & & 121 & $20.9-264$ & 107 & $17.7-183$ & 918 & $398-2933$ \\
\hline
\end{tabular}

n.d.- not detected.

n- number of samples. 
For benzo[a]pyrene ( 5 rings), that is the marker used for evaluating the carcinogenic risk of PAHs in ambient air (Directive 2004/107/EC, 2005), the mean concentration and the standard deviation were $(8.47 \pm 6.55) \times 10^{2} \mathrm{pg} \mathrm{m}^{-3}$ on traffic outdoor and $(7.83 \pm 4.09) \times 10^{2} \mathrm{pg} \mathrm{m}^{-3}$ on indoor non smoking samples, that corresponded to $7 \%$ of the $\Sigma \mathrm{PAHs}$ in both places. Benzo[a]pyrene was also very affected by tobacco smoke, the mean concentration found was $(86.0 \pm 55.7) \times 10^{2} \mathrm{pg} \mathrm{m}^{-3}$, that corresponded to an increase of ca. $900 \%$ relatively to the level detected on $\mathrm{PM}_{2.5}$ collected in traffic outdoor. Lu and Zhu (2007) demonstrated that benzo[a]pyrene concentration of indoor air in smoking homes is significantly higher than in non smoking homes, but the comparison with the level issued by automobile traffic was not made.

In the presence of tobacco smoke, a significant increase on the concentration levels of PAHs was observed, when compared with the outdoor profile samples, affected by high traffic intensity. The PAHs more abundant in smoking $\mathrm{PM}_{2.5}$ samples were chrysene, pyrene and fluoranthene with $25 \%, 15 \%$ and $11 \%$ of $\Sigma \mathrm{PAHs}$ detected, respectively.

The PAHs more affected by tobacco smoke compared with traffic outdoor were: naphthalene and acenaphthene (not detected on outdoor traffic), fluoranthene (increased ca. 3500\%), pyrene (increased ca. 2500\%), chrysene (increased ca. 2300\%), benzo[a]pyrene (increased ca. $900 \%$ ), benz[a]anthracene (increased ca. 700\%), phenanthrene (increased ca. 400\%) and anthracene (increased ca. 370\%). This information is relevant because chrysene, benz[a]anthracene and naphthalene are classified as possible carcinogenic to humans and benzo[a]pyrene as carcinogenic to humans (EPA, 1986; IARC, 2002; IARC, 2008).

To evaluate the influence of traffic outdoor air on the PAHs concentration in $\mathrm{PM}_{2.5}$ detected in indoor non smoking and indoor smoking the $/ / O \mathrm{PAH}$ concentrations ratios were determined (Figure 3).
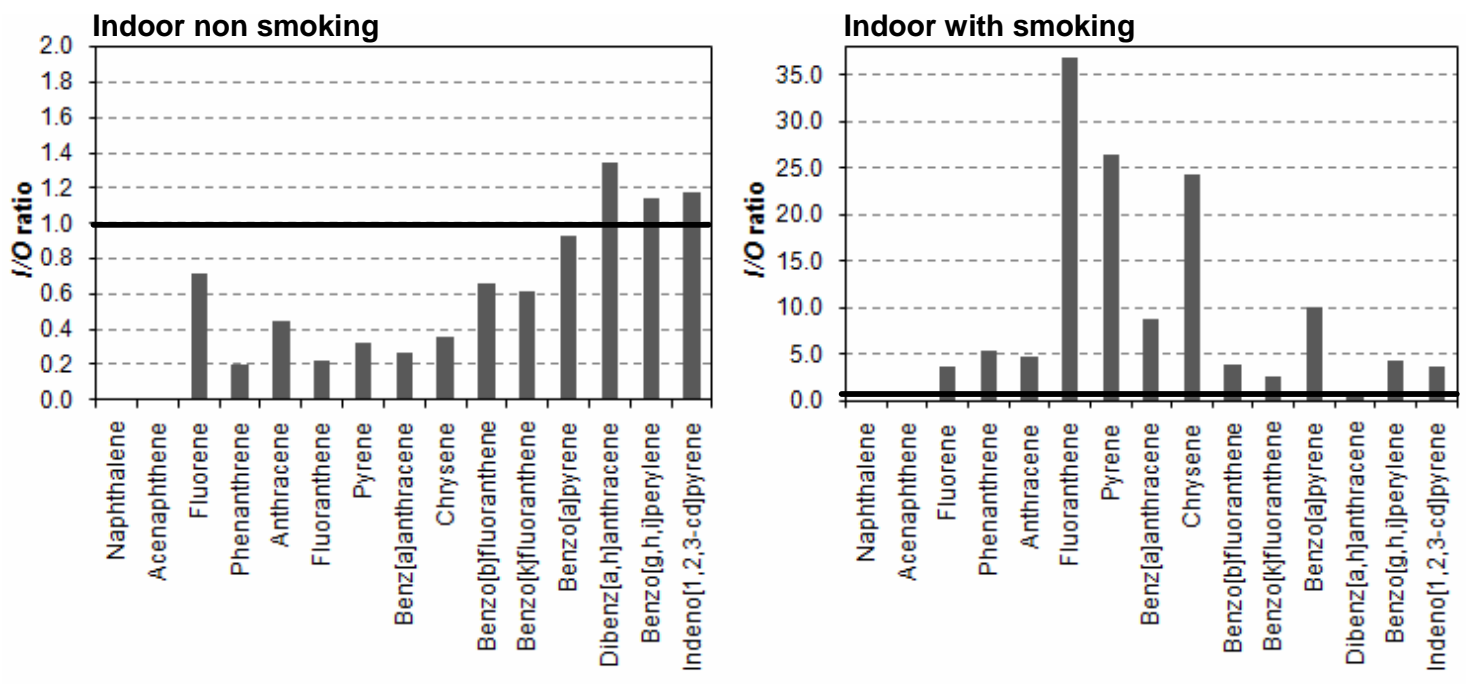

Figure 3. Indoor/Outdoor ratio of the individual PAH concentrations measured in this study

The I/O PAHs ratios without the influence of tobacco smoke were less than 1 (Figure 2, indoor non smoking), except for dibenz[a,h]anthracene, benzo[g,h,i]perylene and indeno[1,2,3-cd]pyrene. This observation confirmed the absence of significant indoor PAH sources and suggests that PAH concentrations in indoor non smoking air were dominated by outdoor sources, previously justified by natural ventilation (the selected homes were $1 \mathrm{~km}$ far from the outdoor traffic site). These results were consistent with the data reported by other authors (Sanderson and Farant, 2004).

In the presence of tobacco smoke the $/ / O \mathrm{PAHs}$ ratios were much higher than 1 (ranged between 2.7 and 37 (Figure 3, indoor with smoking). The high values of this ratio indicate a strong relationship between the tobacco smoking and PAHs emissions, which proves that tobacco is the most important PAHs pollution source on indoor air. The only exception was for 
dibenz[a,h]anthracene, which $I / O$ ratio was 0.43 demonstrating that this compound is more characteristic of traffic emissions than tobacco smoke.

The data reached in this study question the quality of breathable air existing in indoor spaces. The implementation of a policy of indoor air quality is undoubtedly necessary and urgent in the fight and awareness of people to tobacco smoke.

\section{CONCLUSIONS}

Indoor $\mathrm{PM}_{2.5}$ concentrations were significantly influenced by the presence of traffic and tobacco smoking emissions. The health effects associated with $\mathrm{PM}_{2.5}$ justifies the need to continue developing efficient strategies to protect human health.

PAHs in $\mathrm{PM}_{2.5}$ are also affected by the PM traffic and tobacco smoke emissions. PAHs with higher molecular weight (5-6 rings), that are classified as carcinogenic, were preferentially found in the outdoor traffic and indoor non smoking sites. The I/O PAHs ratios without the influence of tobacco smoking allowed concluding that PAHs concentrations in indoor air were dominated by outdoor traffic emissions.

The presence of tobacco smoke emissions increased significantly PAHs concentrations on average about 1000 times more, with a significant increase on the concentration levels of the following PAHs: fluoranthene, pyrene, chrysene, benzo[a]pyrene and benz[a]anthracene, when compared with the outdoor profile samples, affected by high traffic intensity.

Tobacco smoke revealed to be the most important indoor source of PAHs in $\mathrm{PM}_{2.5}$ fraction. However, although the tobacco smoke is listed as the major cause of PAHs, the levels of these compounds in outdoor air may be also considered a serious public health problem, because all people are subject to the conditions of outdoor air, either by direct exposure or through the natural ventilation in indoor spaces.

\section{ACKNOWLEDGEMENTS}

D. Castro and K. Slezakova thank the Fundação para Ciência e para a Tecnologia (FCT) for their PhD fellowship (SFRH/BD/23605/2005 and SFRH/BD/24228/2005, respectively).

\section{REFERENCES}

Bernstein J.A., Alexis N., Bacchus H., Bernstein I.L. Fritz, P., Horner E., Li N., Mason S., Nel A., Oullette J., Reijula K., Reponen T., Seltzer J., Smith S. and Tarlo S.M. (2008), The health effects of nonindustrial indoor air pollution, Journal of Allergy and Clinical Immunology, 121, 585-591.

Cacciola R.R., Sarva M., Polosa R. (2002), Adverse respiratory effects and allergic susceptibility in relation to particulate air pollution: flirting with disaster, Allergy, 57, 281-286.

Castro D., Slezakova K., Oliva-Teles M.T., Delerue-Matos C., Alvim-Ferraz M.C., Morais S. and Pereira M.C. (2009), Analysis of polycyclic aromatic hydrocarbons in atmospheric particulate samples by microwave-assisted extraction and liquid chromatography, Journal Separation Science, 32, 501-510.

Dallarosa J., Teixeira E.C., Meira L. and Wiegand F. (2008), Study of the chemical elements and polycyclic aromatic hydrocarbons in atmospheric particles of PM10 and $\mathrm{PM}_{2.5}$ in the urban and rural areas of South Brazil, Atmospheric Research, 89, 76-92.

Diapouli E., Chaloulakou A. and Spyrellis N. (2008), Indoor and outdoor PM concentrations at a residential environment, in the Athens area, Global NEST Journal, 10, 201-208.

EC (European Union) (2005), Directive 2004/107/EC of the European Parliament and of the Council of 15 December 2004, Official Journal of the European Union, L 23, 3-16.

EPA (1986), Guidelines for carcinogenic risk assessment, Federal Register 51 (185) URL http://www.epa.gov/ncea/raf/car2sab/guidelines 1986.pdf.

Fischer P.H., Hoek G., Van Reeuwijk H., Briggs D.J., Lebret E., Van Wijnen J.H., Kingham S., Elliott P. (2000), Traffic-related differences in outdoor and indoor concentrations of particles and volatile organic compounds in Amsterdam, Atmospheric Environment, 34, 3713-3722.

Guo H., Lee S.C., Ho K.F., Wang X.M. and Zou S.C. (2003), Particle-associated polycyclic aromatic hydrocarbons in urban air of Hong Kong, Atmospheric Environment, 37, 5307-5317. 
Hien T.T., Nam P.P., Yasuhiro S., Takayuki K., Norimichi T., Hiroshi B. (2007), Comparison of particle-phase polycyclic aromatic hydrocarbons and their variability causes in the ambient air in Ho Chi Minh City, Vietnam and in Osaka, Japan, during 2005-2006, Science of the Total Environment, 382, 70-81.

IARC (2002), Some Traditional Herbal Medicines, Some Mycotoxins, Naphthalene and Styrene. IARC Monographs on the Evaluation of Carcinogenic Risks to Humans 82. International Agency for Research on Cancer, Lyon.

IARC (2008), Air Pollution, Part 1, Some Non-heterocyclic Polycyclic Aromatic Hydrocarbons and Some Related Industrial Exposures. IARC Monographs on the Evaluation of Carcinogenic Risks to Humans 92 - in preparation. International Agency for Research on Cancer, Lyon.

Ilgen E., Karfich N., Levsen K., Angerer J., Schneider P., Heinrich J., Wichmann H.-E., Dunemann L. and Begerow J. (2001), Aromatic hydrocarbons in the atmospheric environment: Part I. Indoor versus outdoor sources, the influence of traffic, Atmospheric Environment, 35, 12351252.

Kishida M., Imamura K., Takenaka N., Maeda Y., Viet P.H., Bandow H. (2008), Concentrations of atmospheric polycyclic aromatic hydrocarbons in particulate matter and the gaseous phase at roadside sites in Hanoi, Vietnam, Bulletin of Environmental, Contamination and Toxicology, 81, 174-179.

Liu Y., Zhu L. and Shen X. (2001), Polycyclic aromatic hydrocarbons (PAHs) in indoor and outdoor air of Hangzhou, China, Environmental Science Technology, 35, 840-844.

Lu H. and Zhu L. (2007), Pollution patterns of polycyclic aromatic hydrocarbons in tobacco smoke, Journal of Hazardous Materials, 139, 193-198.

Lung S.C.C., Wu M.J. and Lin C.C. (2004), Customers exposure to $\mathrm{PM}_{2.5}$ and polycyclic aromatic hydrocarbons in smoking/nonsmoking sections of 24-h coffee shops in Taiwan, Journal of Exposure Analysis and Environmental Epidemiology, 14, 529-535.

Maliszewska-Kordybach B. (1999), Sources, concentrations, fate and effects of polycyclic aromatic hydrocarbons (PAHs) in the environment. Part A: PAHs in air. Polish, Journal of Environmental Studies, 8, 131-136.

Mastral A.M. and Callen M.S. (2000), A review on polycyclic aromatic hydrocarbon (PAH) emissions from energy generation, Environmental Science and Technology, 34, 3051-3057.

Ohura T., Amagai T., Sugiyama T., Fusaya M., Matsushita H. (2004), Polycyclic aromatic hydrocarbons in indoor and outdoor environments and the factor affecting their concentrations, Journal of Environmental Science and Technology, 38, 77-83.

Pereira M.C., Alvim Ferraz M.C.M. and Santos R.C. (2005), Relevant aspects of air quality in Oporto (Portugal): PM10 and O3, Environmental Assessment and Monitoring, 101, 203-221.

Ravindra, Mittal A.K. and Van Grieken R. (2001), Health risk assessment of urban suspended particulate matter with special reference to polycyclic aromatic hydrocarbons: A Review, Reviews on Environmental Health, 16, 169-189.

Rehwagen M., Muller A., Massolo L., Herbarth O. and Ronco A. (2005), Polycyclic aromatic hydrocarbons associated with particles in ambient air from urban and industrial areas, Science Total Environment, 348, 199-210.

Sanderson E.G. and Farant J.P. (2004), Indoor and outdoor polycyclic aromatic hydrocarbons in residences surrounding a soderberg aluminum smelter in Canada, Environmental Science Technology, 38, 5350-5356.

Slezakova K., Pereira M.C, Reis M.A. and Alvim-Ferraz M.C. (2007), Influence of traffic emissions on the composition of atmospheric particles of different sizes - part 1: concentrations and elemental characterization, Journal Atmospheric Chemistry, 58, 55-68.

Slezakova K., Pereira M.C. and Alvim-Ferraz M.C. (2009a), Influence of tobacco smoke on the elemental composition of indoor particles of different sizes, Atmospheric Environment, 43, 486493.

Slezakova K., Castro D., Pereira M.C., Morais S., Delerue-Matos C. and Alvim-Ferraz M.C. (2009b), Influence of traffic emissions on the carcinogenic polycyclic aromatic hydrocarbons in outdoor breathable particles, Journal of the Air \& Waste Management Association, in press.

Vardar N., Esen F., Tasdemir Y. (2008), Seasonal concentrations and partitioning of PAHs in a suburban site of Bursa, Turkey, Environmental Pollution, 155, 298-307.

WHO (2000), Air quality guidelines, World Health Organization Regional Publications, Copenhagen. 